\title{
La oposición en el procedimiento de otorgamiento de concesiones marítimas
}

\author{
THE OPPOSITION IN THE PROCEDURE FOR GRANTING MARITIME CONCESSIONS
}

\author{
CAMILO MiroseVic Verdugo* \\ XIMENA VILCHES VILLENA*
}

\begin{abstract}
RESUMEN
El derecho a oponerse constituye una de las piezas centrales en el procedimiento de otorgamiento, renovación y modificación de concesiones marítimas. Su configuración permite hacer efectivo el derecho de los interesados accesorios a ser oidos en el curso del procedimiento, lo que, junto con mejorar la calidad de las decisiones, sirve como mecanismo de ponderación de intereses y resolución de conflictos, reduciendo su impugnación judicial. Considerando las particularidades presentes en la asignación de usos temporales sobre el dominio público marítimo-costero, la regulación de las concesiones marítimas ha reconocido, desde hace más de cinco décadas, la existencia de terceros potenciales afectados en el procedimiento a través del derecho a oponerse al otorgamiento de una concesión. La nueva regulación pretende superar las deficiencias que afectaban al diseño normativo anterior, particularmente en lo relativo a la publicidad y celeridad del procedimiento administrativo.
\end{abstract}

\section{PALABRAS CLAVES}

Concesiones marítimas, derecho a oponerse, interesados en el procedimiento administrativo.

\section{ABSTRACT}

The right to oppose arises as a central element in the administrative procedure established for granting maritime concessions. Its legal design allows the interested parties to exercise the right to be heard, improving the quality of the administrative decisions as well as serving as a space to prevent and resolve the conflict between multiple interests. Taking into account the specific characteristics of the power to manage the maritime domain, the intervention of third parties through the opposition during the procedure has been recognized since more than five decades. The recently enacted regulation on the maritime concessions deals with the shortcoming of the former regime related to the publicity of the procedure and the right to have a decision in reasonable time.

\section{KEYWORDS}

Maritime concessions, opposition in administrative procedure, third parties in administrative procedure.

\section{Introducción}

El significativo potencial marítimo de Chile, con sus 4.700 kilómetros de costa, reclama la necesidad de gestionar en forma eficaz el espacio costero para el desarrollo de las distintas actividades que en él se realizan. En razón del incremento de la presión por su utilización a través

\footnotetext{
* Abogado, Magíster en Derecho. Profesor de Derecho Administrativo en la Universidad Central de Chile, Santiago, Chile. Correo: mirosevic@gmail.com.

** Profesora de Castellano, Egresada de Derecho. Revisora Técnica en el Departamento de Asuntos Marítimos de la Subsecretaría para las Fuerzas Armadas, Santiago, Chile. Correo: ximena.vilches.villena@gmail.com.
} 
de sus diversas modalidades (esparcimiento, turismo, pesca, acuicultura, actividad portuaria, comercial, industrial, energética, etc.) y reconociendo que dicho espacio es un bien extenso, pero limitado, el ordenamiento jurídico atribuye a la Administración potestades de ordenación y asignación de uso sobre el dominio público costero-marítimo.

Producto de la necesidad de compatibilizar esos múltiples intereses sobre el borde costero y asegurar la satisfacción del interés general, los bienes que integran el demanio marítimo del Estado se encuentran sujetos a un régimen jurídico público ${ }^{1}$ que considera un mecanismo de asignación de uso temporal sobre estos, así como la existencia de un conjunto de potestades concurrentes atribuidas a distintos órganos de la Administración. De esta forma, el uso privativo sobre una porción del mar territorial, playas y terrenos de playa puede asignarse a un particular o a una entidad pública por tiempo limitado y para la realización de una actividad o proyecto específico, a través de la técnica concesional.

Para tal efecto, el ordenamiento establece un procedimiento administrativo específico destinado a otorgar el aprovechamiento privativo de una porción del litoral, encargado al Ministerio de Defensa Nacional (en lo sucesivo 'el Ministerio').

Considerando que la decisión de asignar temporalmente el aprovechamiento de estos bienes tiene la potencialidad de impactar negativamente a propietarios de terrenos privados colindantes o a otros concesionarios, o de mermar el uso común que sobre algunos de esos espacios corresponde a todos los habitantes, se ha previsto dentro del procedimiento administrativo la posibilidad de que terceros puedan deducir oposición a la solicitud de concesión marítima cuando ella les irrogue perjuicio.

En ese contexto, el objeto del presente trabajo es revisar la configuración de este mecanismo de ponderación de intereses y prevención de conflictos, a partir de la fisonomía que le asigna la nueva regulación del procedimiento de concesiones marítimas, contenida en el D.S. $\mathrm{N}^{\circ}$ 9, de 2018, del Ministerio de Defensa Nacional, que sustituye el Reglamento sobre Concesiones Marítimas ('el Reglamento'), cuya reciente entrada en vigencia ha tenido lugar el 1 을 de septiembre de 2018.

\section{Dominio público marítimo-terrestre y régimen concesional}

\subsection{Aspectos generales}

Como resultado de una extensa tradición de uso común que se remonta al Derecho romano, nuestro ordenamiento recoge la naturaleza demanial del mar territorial, la playa y las zonas en que se produce la interacción del mar con la tierra. La teoría clásica del Derecho administrativo nos enseña que las particularidades de estos espacios determinan su sometimiento a un régimen jurídico público de inalienabilidad ${ }^{2}$, lo que genera su inembargabilidad e imprescriptibilidad. Ello justifica, asimismo, la presencia de órganos de la Administración con poderes de ordenación, asignación y policía para gestionar y preservar la integridad del demanio.

Tributario de la regulación que efectuaba el Derecho romano ${ }^{3}$, recogida en las Partidas ${ }^{4} y$ luego en el Derecho indiano, nuestro Código Civil reconoce, en la categoría de cosas comunes a todos los hombres y por ende insusceptibles de apropiación privada, el alta mar (art. 585). A su turno, califica el mar adyacente y sus playas como bienes nacionales cuyo uso pertenece a todos los habitantes (art. 589), disponiendo que el aprovechamiento no intensivo - navegación,

\footnotetext{
${ }^{1}$ Como indica Nemesio Rodríguez, la condición de dominio público de un bien designa el especial régimen jurídico a que se encue ntra sometido en razón de su carácter. RODRÍGUEZ (1967), p. 292.

${ }^{2}$ LEGUINA (2005), p. 10.

${ }^{3}$ MÍGUEZ (2014), p. 13

${ }^{4}$ CONDE (1974), p. 432
} 
tránsito y otros usos lícitos - sobre ellos se encuentra sujeto a las prescripciones de ese cuerpo normativo y a las contenidas en las ordenanzas que se dicten (art. 598).

No obstante que históricamente los bienes que integran el demanio marítimo-costero fueron de libre utilización, por razones de soberanía y para asegurar la compatibilidad del uso particular con el uso común ${ }^{5}$, el monarca y luego el Estado intervinieron en la gestión de este espacio ${ }^{6}$. Esa intervención estatal se vio reforzada en la medida que creció el interés por la utilización del borde costero, particularmente en actividades productivas y recreacionales, fenómeno relativamente reciente asociado a los avances tecnológicos.

\subsection{Naturaleza de los bienes que integran el espacio costero-marítimo}

En concordancia con lo previsto por el legislador civil, el D.F.L. N ${ }^{\circ} 340$ de 1960 del Ministerio de Hacienda, Ley sobre Concesiones Marítimas ('Ley sobre Concesiones Marítimas'), establece que el mar territorial y las playas de mar tienen la naturaleza de bienes nacionales de uso público y quedan entregados al control, fiscalización y supervigilancia del Ministerio de Defensa Nacional. Igual condición comparten los ríos y lagos, y sus playas, cuando son navegables por buques de más de cien toneladas, los que no serán abordados en este estudio.

Por otra parte, el mismo cuerpo legal sujeta a dicha competencia a los terrenos de playa ubicados en una franja de hasta ochenta metros medidos de la línea de más alta marea, los que presentan la naturaleza de bienes fiscales. Cabe señalar que esta última clase de bienes no estará presente cuando existan terrenos privados que sean colindantes con el mar y se encuentren inscritos en esos términos, cuestión frecuente respecto de títulos de antigua data. En este supuesto, el legislador considera la obligación de esos propietarios colindantes de permitir el acceso gratuito a las playas cuando no existan otras vías disponibles, limitación al dominio que ha sido objeto de diversas controversias en sede constitucional $^{7}$ y que recientemente se ha visto reforzada a través de un régimen sancionatorio ${ }^{8}$.

Respecto de estos terrenos de playa corresponde precisar que, para el Derecho administrativo, los bienes fiscales o patrimoniales del Estado se encuentran destinados a servir a los órganos públicos. De ahí que se predique que su régimen sea el Derecho común, con algunas excepciones expresas, como la inembargabilidad cuando son indispensables para el cumplimiento de una función pública.

Sin embargo, debe anotarse que estos terrenos, cuando se ubican en el borde costero, escapan a las características tradicionales que se predican de los bienes patrimoniales. Por una parte, porque no se trata de inmuebles asignados a la Administración por ser necesarios para el cumplimiento de sus funciones, razón que, precisamente, justifica que se otorguen en concesión a otras Administraciones y a particulares. De otro lado, y no obstante no estar destinados por definición al uso público, estos bienes fiscales se encuentran excluidos, por regla general, del tráfico jurídico, careciendo el Ministerio de Defensa Nacional de la potestad de enajenarlos. Dicho en otros términos, se trata de inmuebles solo concesionables y no apropiables. La única excepción a esta regla - que prácticamente no recibe aplicación- no se encuentra prevista en la Ley sobre Concesiones Marítimas, sino que en el D.L. N ${ }^{\circ} 1.939$, de 1977. Luego de establecer que los terrenos de playa "no podrán enajenarse a ningún título" y que "sólo serán susceptibles de actos de administración", su art. 6o permite excepcionalmente su enajenación a ciertas

\footnotetext{
${ }^{5}$ En las Siete Partidas se permitía construir libremente en la ribera de la mar (Ley IV), siempre que "non se embargue el uso comunal de la gente". Esta construcción requería de autorización de la autoridad, lo que, a juicio de Miralles, perseguía velar por el mantenimiento del uso común. MIRALLES (1992), p. 22.

${ }^{6}$ El interés del Derecho romano resultaba, entonces, en la necesidad de compatibilizar los usos realizados por los particulares, estableciendo como únicas limitaciones a su libre aprovechamiento el perjuicio a terceros y las restricciones expresas previstas por el Emperador o el Senado. CELUME (2013), p. 38.

${ }^{7}$ FUENTES (2013), pp. 418-419.

${ }^{8}$ La ley № 21.149, de 2019, incorporó un inciso al art. 13 del D.L. № 1.939, de 1977, disponiendo que la contravención a la prohibición de cerrar y obstaculizar las vías de acceso será sancionada con multa, aplicada por los juzgados de policía local.
} 
personas jurídicas chilenas sin fines de lucro, siempre que se cuente con informe favorable de la Comandancia en Jefe de la Armada.

Desde el punto de vista práctico, los terrenos de playa constituyen una porción que muchas veces es de difícil delimitación y que, por esa circunstancia y por su contigüidad con la playa, en los hechos se terminan comportando como si se tratara de bienes de uso público, sometidos por tanto al uso común. En efecto, si se observa la situación de un balneario, resulta evidente que las actividades no intensivas como la recreación se desarrollan, de igual manera, en la playa y en los terrenos de playa. Por lo demás, la condición de playa y de terreno de playa de un espacio es variable, ya que, como ha señalado la Contraloría General de la República ${ }^{9}$, los cambios en la morfología generados por el retiro del mar o su subida, deben traducirse en una modificación de la línea de playa, lo que provoca, entonces, que un bien que antes era nacional de uso público - playa -, ahora pase a ser bien fiscal - terreno de playa- o viceversa ${ }^{10}$.

En definitiva, a partir de lo señalado es posible afirmar que los terrenos de playa si bien tienen la condición de fiscales, tanto por su regulación como por las situaciones fácticas que se presentan, se asimilan más a los bienes nacionales de uso público, que a los bienes patrimoniales del Estado en su concepción tradicional.

\subsection{Aprovechamiento privativo del espacio costero-marítimo mediante el régimen concesional}

A partir de la regulación contenida en el Código Civil, especialmente en su art. 598, se concluye que el mar territorial y las playas se encuentran sujetos a un régimen de utilización libre, gratuito e igualitario. Así, al uso general de los habitantes que el legislador civil identifica con actividades no intensivas como el tránsito o la navegación, contrapone el uso y goce exclusivo que se asigna a un particular a través de un "permiso especial de autoridad competente", que lo habilita para construir sobre bienes.

Esa utilización privativa y, por tanto, extraordinaria, reclama la existencia de un título administrativo ${ }^{11}$. En nuestro ordenamiento ese título es denominado en términos genéricos concesión marítima, cuyas especies son las concesiones mayores y menores, destinaciones marítimas y los permisos y autorizaciones, según dispone el art. $4^{\circ}$ inc. final del Reglamento. Asimismo, constituye también una especie de concesión marítima la concesión de acuicultura, la que, producto de la especialidad de la actividad que ampara, cuenta con una regulación propia contenida en la Ley General de Pesca y Acuicultura y en el reglamento respectivo, la que no será objeto de análisis.

Según se desprende de lo establecido en la Ley y el Reglamento en examen, la concesión marítima se erige como un título de ocupación que habilita al titular para aprovechar en forma privativa una porción de bienes fiscales o nacionales de uso público sometidos a la competencia del Ministerio. Este título, que se concretiza en un acto administrativo - decreto o resolución, no solo incrementa la esfera jurídica del concesionario asignándole el derecho a utilizar en forma exclusiva esos bienes, sino que, además, define la situación jurídica del titular, fijando sus derechos y obligaciones.

De esta forma, el titular de la concesión marítima se encuentra sometido a un estatuto jurídico-público, integrado por la normativa (legal y reglamentaria) y por el propio título (la concesión $)^{12}$. Con todo, debe precisarse que en nuestro ordenamiento la concesión se presenta

\footnotetext{
${ }_{9}^{9}$ Dictámenes № 46.459, de 2016 y N²4.203, de 2017.

${ }^{10}$ Ello puede derivar, asimismo, en que lo que era terreno de playa de competencia del Ministerio de Defensa pase a ser bien fiscal administrado por el Ministerio de Bienes Nacionales o aumente o disminuya la cabida de las propiedades particulares colindantes. ${ }^{11} \mathrm{Al}$ respecto, el profesor Ramón Martín Mateo distingue tres modalidades de utilización del dominio público: el uso común general que corresponde a todos por igual sin que el aprovechamiento de unos entorpezca el de otros; el uso común especial caracterizado por su intensidad u otras circunstancias que pueden implicar restringir el uso de otros, lo que obliga a su legitimación vía autorización; y el uso privativo o excluyente, que requiere concesión. MARTíN (1985), pp. 33-34.

12 FUENTETAJA (2003), p. 108.
} 
como un título de ocupación y no de actividad, en el sentido de que ella solo ampara el uso del espacio para una actividad y por un lapso específicos, mas no otorga al titular las autorizaciones y permisos necesarios para su desarrollo concreto ${ }^{13}$, los que deben ser tramitados de forma independiente. Esto implica, consecuentemente, que las condiciones impuestas por los distintos órganos de la Administración en la concesión y en los permisos y autorizaciones, pueden ser exigidas también de modo independiente ${ }^{14}$. Sin embargo, el destino de los permisos y autorizaciones requeridos para el desarrollo de la actividad no será indiferente para la relación concesional, particularmente cuando ello se traduzca en la imposibilidad del titular de construir o ejercer la actividad comprometida en los plazos previstos, pudiendo incurrir en la causal de caducidad por incumplimiento del objeto o de las obligaciones del concesionario. A su vez, la existencia de la concesión se presenta como requisito para la obtención de algunos de esos permisos y autorizaciones que habilitan el desarrollo de la actividad, como sucede con las patentes comerciales y de alcoholes, las que no podrán otorgarse al interesado que no cuente con un título administrativo que ampare la ocupación del espacio ${ }^{15}$.

El otorgamiento de la concesión marítima y la consiguiente exclusión del uso común de una porción del demanio, se justifica en el interés público presente en la actividad que se desarrollará en él o en la necesidad estratégica de ocupar una parte del territorio estatal. Es precisamente por ello que el cumplimiento del objeto de la concesión constituye la principal obligación del concesionario, puesto que para la Administración no es indiferente que el espacio asignado sea o no utilizado. El uso óptimo del dominio público representa el interés general que justifica la existencia del régimen concesional ${ }^{16}$ y las potestades de intervención de la Administración a lo largo de toda la relación Estado-concesionario se encuentran orientadas no solo a preservar la integridad del demanio, sino también a verificar el cumplimiento de las obligaciones del concesionario para que la actividad comprometida se desarrolle efectivamente.

En este sentido, para velar por que esa utilización no menoscabe el interés general, el ordenamiento consagra un cúmulo de mecanismos preventivos y represivos. Partiendo por estos últimos, la existencia de poderes de fiscalización y sanción a cargo de la Autoridad Marítima y del Ministerio se orientan a asegurar que, una vez obtenida la concesión, su titular dé cumplimiento a las obligaciones contenidas en el acto administrativo y a la regulación aplicable. Respecto de los primeros, la existencia de la garantía por costos de retiro de instalaciones y otros gastos derivados de la concesión apunta a que el ejercicio del derecho de uso privativo no merme la integridad de los espacios. Del mismo modo, los informes preceptivos que emiten otros órganos de la Administración durante el procedimiento permiten verificar, anticipadamente, que la actividad y las obras que se pretenden ejecutar sean jurídicamente viables, evitando que la concesión sea otorgada y luego el proyecto no pueda ser ejecutado. En ese contexto, el trámite de oposición dentro del procedimiento se presenta, desde esta perspectiva, como un mecanismo que permite a la Administración contar con elementos de juicio acerca de los efectos que respecto de terceros puede generar acoger la solicitud de concesión, de modo que la actividad pueda ser desarrollada efectivamente y no se frustre la relación concesional a través de impugnaciones que conduzcan a la extinción del acto administrativo.

\footnotetext{
${ }^{13}$ Así, por ejemplo, el titular deberá obtener el permiso urbanístico, la autorización sanitaria y la resolución de calificación ambiental, cuando corresponda.

${ }^{14}$ RODRÍGUEZ (1993), p. 301.

${ }^{15}$ Dictamen №15.711, de 2011.

${ }^{16}$ FUENTES (2013), p. 423.
} 


\section{El derecho a oponerse y sus antecedentes normativos}

\subsection{Ampliación del concepto de interesado como fundamento del derecho de oposición}

La concepción original de que el procedimiento administrativo reconocía como únicos sujetos a la Administración y a un interesado, que era normalmente quien lo promovía con una solicitud, fue cediendo frente a la constatación de que, en la realidad, muchas veces las decisiones que derivaban de esa relación bilateral terminaban impactando negativamente la esfera jurídica de terceros.

Esta situación, que se presenta con nitidez en el ámbito urbanístico en que el otorgamiento de la licencia para construir termina afectando a los vecinos ${ }^{17}$, impulsa la ampliación de la concepción de interesado y el reconocimiento de que algunos actos administrativos generan una verdadera relación jurídica multilateral.

A partir de ello, las normas de procedimiento administrativo reconocen la condición de interesado no solo a quien lo inicia - que pasa a denominarse interesado principal o promotor, sino a quienes pueden resultar afectados con la decisión que en este se adopte. Respecto de estos últimos, incluidos en el concepto interesados accesorios, la primera respuesta del Derecho fue asignar esta calidad a quienes eran titulares de derechos que serían alcanzados por el acto terminal.

Con posterioridad, a partir del desarrollo del concepto de "interés" como categoría amparada por el ordenamiento administrativo, se amplía la titularidad de interesado accesorio a quienes no obstante no ser titulares de un derecho, se encontraban en una posición de proximidad con el objeto del procedimiento que implicaba que la decisión que se adoptara no les sería indiferente.

Como indica Cassagne, el interés se presenta "cuando el administrado se encuentra en una posición de hecho que lo hace más sensible que otros respecto de un acto administrativo ( $v$. gr. la Administración que cierra un camino afecta más directamente a los propietarios de inmuebles con frente en dicha calle)"18. Se dice que existe interés, entonces, cuando del éxito de la solicitud o del contenido de la decisión que se adopte se deriva un beneficio o se evita un perjuicio ${ }^{19}$, concepto este último que no se restringe a un menoscabo económico, sino que es comprensivo de la afectación de un interés de naturaleza material o moral ${ }^{20}$, en la medida que se encuentre amparado por el ordenamiento.

Reconociéndose en la actualidad la existencia de sujetos que pueden asumir la condición de interesados en un procedimiento no obstante no haberlo iniciado, las respuestas ofrecidas por el Derecho administrativo para proteger sus derechos e intereses en esa instancia son diversas. Una fórmula común para alcanzar este objetivo es la obligación de comunicar la existencia del procedimiento administrativo a los potenciales interesados, para efectos de que se apersonen y ejerzan todas las facultades de intervención que les asisten dada su condición de interesados. Es en esta línea en que la etapa de oposición aparece como un medio para permitir que, luego de una notificación o publicación de la solicitud, esos terceros puedan imponerse de la existencia del procedimiento y comparecer manifestando sus observaciones respecto de lo requerido por el interesado principal.

En nuestro ordenamiento, la ley № 19.880 (“LBPA") no considera ningún mecanismo específico al efecto. Por el contrario, este cuerpo legal solo exige comunicar a los interesados la

\footnotetext{
${ }^{17}$ WAHL (2013), p. 80.

${ }^{18}$ CASSAGNE (2013), p. 82.

${ }^{19}$ GONZÁLEZ (2002), p. 162.

${ }^{20}$ LOZANO (2009), p. 268.
} 
decisión final, esto es, el acto conclusivo y no la existencia del procedimiento, deficiencia bastante seria considerando la situación de indefensión en que ello puede traducirse ${ }^{21}$.

Del mismo modo, la LBPA no regula la oposición, cuestión comprensible considerando que se trata de un mecanismo aplicable en escasos procedimientos especiales.

Todavía desde la perspectiva general, conviene precisar que la concepción de interesado presente en la regulación básica del procedimiento incluye no solo a personas naturales o jurídicas privadas, sino también a órganos de la Administración del Estado. En la materia en estudio, aparece como interesado cualquier Administración que solicita una concesión marítima (destinación si se trata de un servicio centralizado; concesión mayor o menor tratándose de los descentralizados). Luego, siendo la Administración titular de derechos e intereses, se admite que la oposición pueda ser formulada por uno de sus órganos integrantes.

\subsection{La oposición como mecanismo de ponderación de intereses y prevención de conflictos}

Siendo el procedimiento administrativo un medio para obtener una actuación efectiva de la Administración, pero también una garantía para los particulares de que sus derechos serán respetados durante ese cauce formal de actuación, la oposición constituye un instrumento encaminado a satisfacer estas dos finalidades del procedimiento.

En efecto, la existencia de una etapa destinada a permitir que terceros que no se han apersonado al procedimiento puedan hacer valer sus consideraciones para que no se acceda a la pretensión del interesado promotor, permite a la Administración contar con elementos de juicio adicionales que nutrirán la decisión final. Desde esta perspectiva, aun cuando la oposición sea desestimada y la Administración acceda a la solicitud, el insumo obtenido puede enriquecer el contenido del acto administrativo, traduciéndose, por ejemplo, en el establecimiento de obligaciones o condiciones para evitar el perjuicio a esos terceros ( $v . g r$. el Ministerio podría establecer la obligación del concesionario de adoptar ciertas medidas de seguridad para no afectar a los concesionarios colindantes o asegurar el acceso a determinado lugar).

Sin duda, la principal finalidad de la inclusión de la etapa de oposición en el procedimiento es materializar su función garantista respecto de terceros que pueden resultar afectados con la decisión que se adopte.

Concretizando estos principios, la oposición constituye una instancia de carácter preventiva dentro del procedimiento que se orienta a evitar la afectación de los derechos o intereses de esos terceros y, por esa vía, precaver una posterior impugnación del acto.

Así, en procedimientos iniciados normalmente a solicitud de interesado, durante el periodo de instrucción se dispone un trámite de publicidad en que se da a conocer la existencia de la solicitud y su objeto, y se establece un espacio de tiempo acotado para que los terceros que se estimen afectados con la solicitud puedan oponerse ${ }^{22}$.

Finalizado dicho periodo, la Administración pondera las alegaciones de los oponentes y los intereses en cuestión y, si considera que la estimación de la solicitud puede afectar sus derechos o intereses o el interés público, acogerá la oposición y dictará un acto desestimatorio. Con ello se resguardan los derechos e intereses de sujetos que se han apersonado en el trámite de oposición y, a la vez, se disminuye la probabilidad de que el acto terminal sea impugnado en caso de acogerse la solicitud, por no haberse escuchado a los interesados accesorios. En cualquier caso, la comparecencia o incomparecencia en la instancia de oposición no impide a los interesados ejercer los demás medios de impugnación ${ }^{23}$. pero normalmente será más fácil defender un acto en que se escuchó a los potenciales afectados con la decisión que aquel en que esos interesados no fueron considerados.

\footnotetext{
${ }^{21}$ Las únicas cuestiones que se encaminan a este objetivo son la audiencia previa en el procedimiento de invalidación (art. 53); la comunicación a los demás interesados cuando se presentan cuestiones conexas (art. 41); y el deber de notificar la interposición de los recursos administrativos - que origina el procedimiento de impugnación - a los demás interesados (art. 55).

${ }^{22}$ MIROSEVIC (2013), p. 136.

${ }^{23}$ MIROSEVIC (2013), p. 150
} 
Deducida oposición por un sujeto potencialmente afectado, se produce la pluralidad de intervinientes y el procedimiento asume un carácter contradictorio, debiendo la Administración asegurar la participación igualitaria de todos los intervinientes, en cumplimiento del principio de imparcialidad. El resultado de esta etapa favorecerá solo a uno de los interesados, a menos que se alcance un acuerdo entre ellos.

Como puede advertirse, la oposición en el procedimiento administrativo descansa en tres principios fundamentales: publicidad, contradictoriedad e imparcialidad ${ }^{24}$. La publicidad permite que los titulares de derechos o intereses que no se han apersonado en el procedimiento puedan imponerse del contenido del mismo, lo que se verifica usualmente a través de la carga procedimental del interesado promotor de dar a conocer la existencia de la solicitud y del procedimiento; el principio de contradictoriedad faculta a los particulares para defender esos derechos o intereses, garantía que se concretiza mediante la formulación de oposición; y el de imparcialidad impone a la Administración el deber de obrar con objetividad en la ponderación de esos distintos intervinientes, sin preferencia o animadversión hacia ningún interesado.

La oposición es, entonces, la manera en que se concretiza la intervención de estos interesados accesorios en distintos procedimientos administrativos en que el acto tiene un potencial significativo de impactarles negativamente. En estos términos ha sido reconocido en los procedimientos de constitución de derechos de aprovechamiento de agua; concesiones de telecomunicaciones; internación de organismos vegetales vivos modificados; patente $u$ otras especies de propiedad industrial; regularización de la pequeña propiedad raíz; entre otros ${ }^{25}$.

Del mismo modo, el reconocimiento del derecho a oponerse en un procedimiento permite a la Administración resolver un conflicto jurídico que, de no existir la instancia, se canalizaría exclusivamente por vía jurisdiccional a través de la impugnación del acto terminal, generando un gasto de recursos del aparato administrativo y una sobrecarga innecesaria del sistema judicial. Desde esta óptica, la oposición favorece la resolución anticipada de conflictos y se orienta a precaver esa impugnación; ello, naturalmente, con la limitación de que lo resuelto en esa instancia podrá ser revisado en sede judicial.

\subsection{Evolución de la regulación del trámite de oposición en el procedimiento de concesiones marítimas}

Desde sus orígenes, la regulación en torno a las concesiones marítimas consideró la posibilidad de que terceros se opusieran al otorgamiento del acto concesional. El presupuesto de la oposición en este ámbito reside en que, producto de la proximidad física con los espacios que están siendo solicitados en concesión, su otorgamiento puede afectar a personas distintas del solicitante. Si bien la normativa no es explícita en el sentido de especificar el contenido de ese perjuicio, es posible adelantar que, dada la dificultad material de fijar los límites de los espacios que pueden ser concesionables respecto de los bienes de propiedad particular, el trámite de oposición se presentaba originalmente como una fórmula destinada a que los vecinos colindantes pudiesen resguardar los límites de sus propiedades, así como los beneficios que les reportaba colindar con la playa.

La única disposición vinculada con la materia que se contiene en la Ley sobre Concesiones Marítimas corresponde a su art. 5, precepto que no regula directamente la oposición y que será estudiado más adelante. Producto de lo anterior, el análisis se centrará en los distintos reglamentos de concesiones marítimas dictados desde mediados del siglo XX.

El Reglamento General sobre Concesiones Marítimas contenido en el D.S. №12, de 1949, del Ministerio de Defensa Nacional, estableció que, una vez recibida la solicitud, la Autoridad Marítima debía ponerla en conocimiento de "los ocupantes de bienes colindantes con el que se

\footnotetext{
${ }^{24}$ MIROSEVIC (2013), p. 136.

${ }^{25}$ MIROSEVIC (2013), pp. 149-151.
} 
solicita" (art. 3 inc. final). A su turno, esa entidad debía informar al Ministerio acerca de "si hay oposición escrita de terceros", para la "resolución suprema que corresponda" (art. 4 letra d y art. 9). Como puede advertirse, se consideraba una medida de publicidad de la solicitud respecto de ocupantes de los espacios contiguos al lugar requerido en concesión, sin restringirla a propietarios ni a concesionarios, así como el derecho a oponerse por escrito a la solicitud.

Por su parte, el Reglamento General sobre Concesiones Marítimas que lo sucedió aprobado por el D.S. N¹56, de 1961- contenía varias disposiciones sobre la materia, siendo el cuerpo normativo más desarrollado hasta la dictación del reglamento actual. Como primer aspecto, establecía que en los bienes bajo tuición del Ministerio "no se otorgarán concesiones si se trata de sectores que sean de habitual uso o tránsito público" ni "tratándose de bienes que se encuentren en litigio entre el fisco y los particulares" (art. 9), restricciones que estaban orientadas a evitar que el título administrativo afectara el uso común o pudiese ser posteriormente impugnado por recaer sobre bienes cuyo dominio se encontraba en disputa. Un segundo aspecto a comentar es que ordenaba que toda concesión se entendía otorgada sin perjuicio de derechos adquiridos por terceros a cualquier título legítimo (art. 12), regla que fue reiterada en todos los reglamentos posteriores hasta el actual. El mismo precepto disponía que "Los que con su otorgamiento se consideren perjudicados o se opongan, fundamentarán por escrito su oposición", especificando a continuación tres causales taxativas en que esta podía fundarse: a) cuando las obras obstruyeran la vista al mar de una casa existente en terreo particular adyacente; b) cuando ese propietario privado manifestara la intención de solicitar el terreno de playa o la playa para ampliar industrias instaladas; y c) cuando dicho propietario expresara su deseo de solicitar los espacios contiguos para construir una casa o instalar industria o balneario.

De la sola lectura de dichas causales se aprecia que el derecho a oponerse tenía como finalidad otorgar protección a un interés individual, toda vez que las tres habilitaban al propietario de los terrenos particulares colindantes al sector donde se pretendía la concesión marítima. Con todo, la existencia de la causal solo servía de fundamento a la oposición y no implicaba una preferencia al propietario contiguo respecto del solicitante.

Por último, como medida de publicidad la Autoridad Marítima debía informar por escrito al propietario colindante las características de la concesión que se estaba solicitando, otorgándole un plazo máximo de 15 días para formular sus objeciones u oposiciones (art. 63 letrag).

En suma, este cuerpo normativo restringió la oposición al propietario de terrenos particulares, regulando en detalle las causales en que podía fundarse, y contempló un medio de publicidad de la solicitud para permitir el ejercicio de ese derecho. A su vez, estableció acertadamente un espacio de tiempo para el ejercicio del derecho a oponerse, cuestión gravitante en todo diseño normativo. Al mismo tiempo, privilegió el uso común al no otorgarse concesiones cuando pudiesen afectarlo, y buscó evitar concesionar espacios en conflicto judicial con privados, reglas que no fueron recogidas en los reglamentos que le siguieron.

Posteriormente, el Reglamento contenido en el D.S. N²23, de 1968 facultaba al Ministerio para denegar una solicitud de concesión cuando terceros alegaran que ella les irrogaría perjuicios (art. 9 inc. 2), agregando que "la resolución que recaiga sobre ella [la oposición] no será susceptible de recurso alguno". A partir de este reglamento cualquier tercero que estimara que la concesión le ocasionaría un perjuicio, podía oponerse a su otorgamiento, no siendo necesario que se tratara de un propietario colindante. Tampoco se enumeran causales taxativas para oponerse, el ejercicio de ese derecho no queda circunscrito a una oportunidad procesal, ni se contempla un mecanismo de publicidad como en sus predecesores. Solo se precisa que la oposición será calificada por el Ministerio y que la decisión no podrá ser revisada. La deficitaria configuración de la oposición que efectúa este reglamento es reproducida en los textos que lo reemplazan, hasta la dictación del D.S. №9, de 2018.

Luego, el D.S. N660, de 1988 mantuvo ese diseño normativo, agregando únicamente un plazo de 30 días para que el solicitante lograra con los oponentes un acuerdo (art. 9). Por 
consiguiente, se entregó a ellos la posibilidad de convenir una solución al conflicto que permita continuar el procedimiento, sin mediar una decisión de la Administración. No obstante, si dentro del plazo señalado no se alcanzaba dicho acuerdo "el Ministerio resolverá, luego de calificar la oposición, pudiendo acoger o denegar la solicitud, y dicha resolución no será susceptible de recurso alguno" (art. 9).

Finalmente, el artículo 8 del D.S. $\mathrm{N}^{\circ} 2$, de 2005, que sustituye el Reglamento sobre Concesiones Marítimas, reprodujo la deficitaria regulación contenida en el texto anterior, prescindiendo únicamente de la frase "dicha resolución no será susceptible de recurso alguno", en aplicación de lo previsto en las leyes №s18.575 y 19.880, que reconocen la procedencia a todo evento del recurso de reposición, y el de revisión a partir de ese último cuerpo legal.

\subsection{Deficiencias que evidenciaba la regulación anterior}

Con el objeto de exponer los cambios que introdujo el reglamento que acaba de entrar en vigencia, se efectuará una revisión de las principales insuficiencias de la regulación anterior, contenida en el D.S. №2, de 2005, las que, según se indicó, se arrastraban desde el reglamento de 1968. Para ello, el análisis se centrará en tres dimensiones, que consideramos de mayor relevancia y que condujeron a la nueva reglamentación.

La primera deficiencia que debe observarse es que, si bien la instancia de oposición en el procedimiento buscaba resguardar los derechos e intereses de terceros que podían resultar afectados con el otorgamiento de la concesión (art. 8 inc. 2), la normativa no contemplaba ningún medio de publicidad en sus dos aspectos centrales: comunicación del procedimiento y del acto terminal. De una parte, a diferencia de lo que sucedía en los reglamentos de 1949 y 1961, la ausencia de un mecanismo que permitiera dar a conocer la existencia de la solicitud mermaba ostensiblemente la potencial actuación de esos terceros, lo que se agravaba por las deficiencias del sistema informático que impedía tener información actualizada y georreferenciada de las solicitudes en trámite. Tomar conocimiento de la existencia del procedimiento y, por ende, ejercer el derecho a oponerse, dependía de meras contingencias. De otra parte, tampoco se consideraba alguna medida para publicitar la concesión una vez otorgada -la que solo era notificada a su titular-, afectando las posibilidades de los terceros de requerir que ella fuera dejada sin efecto por tener derechos adquiridos legítimamente sobre el objeto de la concesión cuyo libre ejercicio resultaría comprometido, como disponía su art. 8 inc. 1o.

En segundo lugar, la norma no señalaba la oportunidad procedimental en que los terceros podían deducir oposición. La regla se construyó, entonces, a partir de la frase contenida en el aludido art. 8: "podrá denegarse una solicitud de concesión marítima". Por lo tanto, dado que una solicitud tiene el carácter de tal a contar de su presentación y lo conserva hasta que se dicte el acto administrativo que la resuelve, era posible deducir oposición durante todo el íter procedimental.

Este diseño normativo se tradujo en que el procedimiento podía verse sujeto a dilaciones innecesarias, favoreciendo la presentación de oposiciones carentes de fundamento efectuadas con el ánimo de obstaculizar el otorgamiento de concesiones o de obtener beneficios económicos negociando el desistimiento de la oposición. Lo anterior se agravaba teniendo en cuenta que nada impedía que pudieran interponerse oposiciones sucesivas, ya sea por una misma persona o por diversas, relacionadas o no. Del mismo modo, no se establecían los requisitos de la oposición ni se contemplaba un examen de admisibilidad, lo que se traducía en que todas las que se presentaran eran tramitadas, carecieran o no de fundamento plausible ${ }^{26}$.

\footnotetext{
${ }^{26}$ Sin perjuicio de ello, a partir de la integración del procedimiento de concesiones marítimas con las disposiciones de la ley № 19.880, de 2003, en los últimos años el Ministerio comenzó a inadmitir oposiciones que carecieran manifiestamente de fundamento, exigiendo además que estas cumplieran con los requisitos de la solicitud previstos en el art. 30 de ese cuerpo legal y teniendo por desistidas aquellas en que no subsanaban los defectos en el plazo legal.
} 
La presentación de la oposición obligaba al Ministerio a remitirla a la Autoridad Marítima, la que debía comunicar al interesado el hecho de su interposición, otorgándole el término de 30 días para alcanzar un acuerdo con los oponentes. Paradójicamente, no se consideraba expresamente la formulación de alegaciones o descargos por el solicitante, cuestión que, en todo caso, se admitía en aplicación de las reglas generales -aunque en muchos casos el solicitante podía desconocer que le asistía dicha facultad-. Posteriormente los antecedentes eran remitidos al Ministerio, entidad que debía resolver sobre la oposición. En esa instancia, la Secretaría de Estado podía acoger la oposición y rechazar la solicitud de concesión o, por el contrario, desestimar la oposición y proseguir con el procedimiento. A partir de esa oportunidad, se podía abrir la fase recursiva.

Cualquiera fuere el resultado, lo cierto es que el trámite importaba un retraso significativo - adicional al ya extenso tiempo de tramitación de las solicitudes-, lo que iba en abierta contradicción con los principios de celeridad y de economía procedimental. Por otra parte, la manera en que estaba configurada la oposición permitía el ejercicio de conductas contrarias a la buena fe, haciendo de ella una vía para obstaculizar el procedimiento administrativo.

Finalmente, el tercer aspecto deficitario se evidenciaba cuando el solicitante alcanzaba un acuerdo con los oponentes, supuesto en que el procedimiento continuaba su tramitación, no existiendo pronunciamiento de parte del Ministerio que calificara la suficiencia de lo convenido. Sobre el particular, no se contemplaba la intervención de la Administración durante las conversaciones del solicitante con los oponentes, quedando en manos de estos arribar a una solución, como tampoco que el Ministerio emitiera algún pronunciamiento respecto de la oposición deducida, puesto que la existencia del acuerdo ponía término al trámite de la oposición.

La ausencia de pronunciamiento del Ministerio era particularmente relevante cuando la oposición no se fundaba solo en el perjuicio a un derecho o un interés individual, sino que involucraba un derecho o interés de incidencia colectiva. Esto podía presentarse, v.gr., respecto de una solicitud para construir un puerto, que implicara el cierre de amplios espacios de playa y terrenos de playa, con el único objetivo de evitar que otro concesionario ocupara esos sectores. En esta hipótesis, resulta evidente que los propietarios o concesionarios colindantes podían invocar un perjuicio producto de la restricción que implicaba acoger la solicitud, en razón de la proximidad física con las obras que se proyectaban construir. Sin embargo, concurre con ese interés individual el general en que el acceso a las playas y el disfrute de los bienes nacionales de uso público se restrinja a lo estrictamente necesario. Un acuerdo en que el solicitante se comprometiera a admitir el acceso solo a los oponentes, si bien pudo satisfacer la pretensión de estos últimos, resultaba contrario al interés público. La inexistencia de un mecanismo de control sobre ese acuerdo aparecía, entonces, como una deficiencia del texto reglamentario anterior.

\section{Regulación actual de la oposición en materia de concesiones marítimas}

\subsection{Ley sobre concesiones marítimas}

A pesar de que el derecho a oponerse al otorgamiento de una concesión marítima se encontraba previsto a nivel reglamentario al menos desde 1949, el D.F.L. №340, de 1960 no dedicó ninguna disposición sobre este extremo.

No obstante, su art. 5 se refiere a la relación entre la concesión como título administrativo y la existencia de derechos adquiridos por terceros, materia que se vincula con la oposición en cuanto esta se funda, precisamente, en la existencia de derechos o intereses perjudicados con su otorgamiento. La disposición ordena: "Toda concesión se entenderá otorgada sin perjuicio de los derechos adquiridos por terceros a cualquier título legítimo". 
Esta regla, de origen romano y heredada del derecho hispano ${ }^{27}$, viene a establecer una especie de condición inherente a todo acto concesional, en el sentido de que se mantendrá vigente mientras no se acredite que sobre el espacio que se otorgó en concesión existen derechos de terceros legítimamente adquiridos, supuesto que obliga a dejarla sin efecto.

Esta especial forma de extinguir el acto se explica en el hecho de que, no obstante servir la concesión de título de ocupación, existen al menos tres circunstancias que pueden implicar que aquella termine lesionando derechos de terceros: i) la precariedad del sistema registral respecto de los inmuebles de propiedad fiscal y particular cuya inscripción es de antigua data, así como las variaciones en la cabida producidas por los cambios en las líneas de playa. Ello complejiza la determinación precisa de los límites, pudiendo la concesión invadir esos inmuebles privados o fiscales administrados por otras entidades; ii) las dificultades materiales de delimitación de las concesiones, particularmente las otorgadas antes de la existencia de las técnicas actuales de georreferenciación, lo que puede traducirse en que se otorguen dos concesiones sobre el mismo espacio; y iii) la existencia de órganos con competencia concurrente que pueden superponerse en la asignación de espacios en la zona marítimo-costera. Esta hipótesis tendría lugar si el Ministerio otorgara una concesión sobre un espacio declarado de extensión portuaria por el Ministerio de Transportes y Telecomunicaciones.

En suma, esos terceros que cuenten con derechos adquiridos legítimamente a cualquier título sobre el espacio que se pretende asignar pueden deducir oposición en la instancia procedimental que se indica en el reglamento o, una vez otorgada la concesión, requerir al Ministerio que ella sea dejada sin efecto. En el evento de que se extinga la concesión por esta última causal, el concesionario podría perseguir la responsabilidad del Fisco por falta de servicio si se acredita que ella fue otorgada habiéndose incurrido en una actuación deficiente ${ }^{28}$.

\subsection{Reglamento sobre concesiones marítimas}

El D.S. №9, de 2018, que aprobó el nuevo Reglamento sobre Concesiones Marítimas, ha introducido diversas modificaciones respecto de los procedimientos sobre concesiones marítimas. En relación con el tema en análisis, la nueva normativa reforma completamente la fisonomía de la oposición, enmarcándola en una etapa específica del procedimiento y acompañándola de mecanismos de publicidad destinados a resguardar los derechos e intereses de los demás interesados, e indirectamente a velar por que la asignación de los espacios se ajuste a la legalidad y se concilie con el interés público.

La materia se encuentra normada en el Título V sobre el "Procedimiento de solicitudes de concesiones mayores y menores y destinaciones marítimas", específicamente, dentro del Párrafo 40 "Régimen de publicidad de la solicitud y oposición". A este respecto, el art. 68 establece:

“Oposición. No se otorgará la concesión mayor o menor o destinación marítima cuando terceros acrediten derechos legítimamente adquiridos sobre el sector solicitado en concesión, siempre que esta impida o sea incompatible con el libre ejercicio de tales derechos.

Sin perjuicio de lo anterior, el Ministerio podrá denegar una solicitud de concesión mayor o menor o destinación marítima cuando terceros aleguen que ella les irrogará perjuicio en sus derechos o intereses legítimos. Con todo, la existencia de otra solicitud de concesión marítima o acuícola sobre el mismo sector será resuelta mediante el procedimiento de sobreposición

\footnotetext{
27 VILLAR (1951), p. 159.

${ }^{28}$ El alcance de la cláusula "sin perjuicio de terceros" respecto de la responsabilidad de la Administración ha sido objeto de discusión en la doctrina española, a partir de la publicación del profesor José Luis Villar Palasí, quien sostuvo que su finalidad era expresar la neutralidad de la Administración respecto a los derechos adquiridos con anterioridad, los que no se verán afectados por la concesión, excluyendo cualquier responsabilidad del Estado tanto respecto del concesionario como de terceros. VILLAR (1951), pp. 165-166. En la otra vereda, el profesor Francisco López critica esta pretendida irresponsabilidad de la entidad otorgante, particularmente cuando el daño se produce por existir otra concesión otorgada con anterioridad. LÓPEZ (2013), p. 473.
} 
regulado en los artículos 17 o 18, según corresponda, y no podrá servir de fundamento para la oposición.

Para tal efecto, cualquier interesado en los términos del artículo 21 de la ley №19.880, podrá formular oposición a la solicitud dentro del plazo de 30 días, contado desde la fecha de publicación del extracto a que se refiere el artículo 66. En el caso de las concesiones mayores, el plazo se contará desde la última publicación que se efectúe.

La oposición deberá cumplir los requisitos establecidos en el artículo 30 de la ley №19.880 y estar dirigida a la Subsecretaría, pudiendo ser presentada tanto en las dependencias de esta como en la Capitanía de Puerto correspondiente, la que deberá informar de ella a la Subsecretaría dentro de las 72 horas siguientes a su recepción y remitirla en el más breve plazo posible. En este caso, la oposición se entenderá presentada en la fecha de su recepción en la Capitanía de Puerto respectiva. Asimismo, deberá estar acompañada de antecedentes que fundamenten el derecho o interés legítimo del oponente y el perjuicio invocado.

Las oposiciones presentadas de forma extemporánea o que adolezcan de manifiesta falta de fundamento o no estén acompañadas de los antecedentes que la sustenten, serán declaradas inadmisibles".

Los principales aspectos de la oposición se desarrollan a continuación.

a) Ámbito de aplicación: El art. 64, que inicia el citado Párrafo 4ํㅡ, determina el ámbito de aplicación de sus disposiciones, indicando que se extienden a las solicitudes de otorgamiento, renovación y modificación sustancial de concesiones mayores o menores o destinaciones marítimas. En consecuencia, no cabe posibilidad de oponerse a otras solicitudes como la de transferencia, que tiene por objeto el cambio del titular de la concesión, o a la de modificación no sustancial, que no conlleva una ampliación del espacio asignado.

b) Publicidad de la solicitud: Como se dijo, la viabilidad del derecho de oposición descansa en la existencia de un mecanismo de publicidad de la solicitud de concesión marítima. Sobre el particular, el Reglamento considera, dado el carácter secuencial y progresivo del procedimiento, el trámite de publicidad como el antecedente a la oportunidad procedimental que permite a esos interesados ejercer su derecho a oponerse.

En este sentido, el artículo 65 consagra la obligación de la Subsecretaría para las Fuerzas Armadas de elaborar un extracto de las solicitudes en las que procede oposición, el que será publicado en su sitio electrónico y contendrá las menciones referidas en el artículo 66 y que se encaminan a proporcionar información sintética sobre la concesión o la modificación que se pretende.

Tratándose de solicitudes de concesión marítima mayor, adicionalmente el interesado deberá publicar, a su costa, dicho extracto en un diario o periódico de circulación regional o local o, en caso de no existir, en un diario o periódico de circulación nacional, dentro de los 45 días siguientes a que se haya admitido a trámite la solicitud. Dado que lo que se persigue es difundir la existencia del procedimiento, resulta acertado que la difusión se realice, además de la publicación electrónica que efectúa la Subsecretaría, en diarios o periódicos respecto de esta clase de concesiones marítimas, que son las que tienen mayor aptitud de afectar a terceros. En esta materia, pudo ser conveniente haber incluido la difusión radial como medio de publicidad, como se prevé en la Ley General de Pesca y Acuicultura respecto de un acto trámite en el procedimiento de concesiones de acuicultura, aunque con una finalidad diversa (art. 67 inc. 6).

El interesado deberá acreditar el cumplimiento de esta carga procedimental incorporando al expediente electrónico copia de la publicación del extracto en el diario o periódico, dentro de los diez días desde que ella se efectúa. Este trámite tiene carácter esencial, de modo que su inobservancia no permite proseguir con la tramitación, debiendo la Subsecretaría denegar la solicitud cuando no se haya efectuado la publicación dentro del plazo previsto por el Reglamento.

c) Supuesto de la oposición: La oposición se estructura sobre la base de dos supuestos distintos, regulados en los incs. 10 y $2 \circ$ del art. 68 . En el primer caso, la oposición se funda en que terceros acrediten derechos legítimamente adquiridos sobre el sector solicitado en 
concesión, cuando ella impida o sea incompatible con el libre ejercicio de esos derechos. En esta hipótesis, la oposición permitirá evitar el otorgamiento de una concesión que, muy probablemente, será contraria a derecho y posteriormente impugnada y dejada sin efecto. Lo anterior dado que las situaciones en que un tercero es titular de un derecho sobre el sector normalmente implicarán que el espacio solicitado en concesión corresponda a dominio particular o que sobre aquel ya exista otro título administrativo, situaciones que obstan a su otorgamiento.

El segundo caso, en tanto, comprende a los terceros que consideran que la concesión solicitada les irrogará perjuicio a sus derechos o intereses legítimos. A diferencia del primer supuesto, en principio no existe un impedimento jurídico para el otorgamiento de la concesión, pues en general ese perjuicio no implica que acceder a la solicitud conlleve dictar un acto contrario a derecho. Siendo así, la oposición será la vía para que la Administración resuelva la colisión de intereses en conflicto, haciendo primar la posición que mejor represente el interés público.

Si bien el precepto no define ni acota ese perjuicio, excluye como sustento de la oposición que esos terceros se encuentren solicitando otra concesión marítima o acuícola sobre el mismo sector, lo que debe resolverse aplicando la regla consagrada para dirimir las sobreposiciones. Esta exclusión viene a ratificar la práctica administrativa del Ministerio de desestimar oposiciones fundadas en la sobreposición de solicitudes, pues el Reglamento consagra un mecanismo específico para la resolución de esta clase de conflictos. Si bien en principio el hecho de encontrarse solicitando el mismo espacio en concesión podría estimarse incluido en el perjuicio a un interés legítimo - siendo la solicitud una mera expectativa, incluso tratándose de una renovación-, esta colisión de intereses en obtener un espacio en concesión se decide de acuerdo con los criterios contemplados en los arts. 17 y 18, según corresponda.

Esta sencilla regla que encauza las sobreposiciones bajo un camino diverso, permite despejar parte importante de las oposiciones que se presentaban bajo la vigencia del texto normativo anterior, las que, a pesar de ser finalmente rechazadas, obligaban a paralizar en los hechos el procedimiento para tramitar la oposición, ante la inexistencia de esta exclusión expresa.

Efectuada esta precisión, debe señalarse que el perjuicio se producirá en el evento de que el otorgamiento de la concesión implique una consecuencia negativa para una persona distinta del interesado principal, que por su relación con el sector solicitado verá desmejorada su situación jurídica o material. Así, entonces, existirá perjuicio a los derechos de terceros cuando la concesión recaiga sobre sectores de dominio particular o sobre espacios en los que ya existe otro título administrativo, como sucedería con las concesiones otorgadas por el Ministerio de Bienes Nacionales (por ejemplo, producto de las variaciones en el límite de competencia entre esta Secretaría de Estado y el Ministerio). Idéntica situación tendría lugar si la solicitud recae en un recinto portuario, en los que no pueden otorgarse nuevas concesiones de acuerdo a la Ley № 19.542, encontrándose la empresa pública respectiva legitimada para deducir oposición sin tener que esperar que la concesión sea otorgada para impugnarla.

Respecto de los intereses, el texto normativo exige que sean legítimos, esto es, que se encuentren amparados por el ordenamiento jurídico y estén en íntima conexión con un interés público, lo que impide que la oposición sea ejercida por un ocupante irregular de los espacios solicitados en concesión, por tratarse de una situación antijurídica. Existirá interés legítimo, en tanto, cuando los propietarios o concesionarios contiguos consideren que la solicitud merma su situación respecto del sector requerido, por ejemplo, por limitar el acceso a la playa o conectar con el mar.

d) Titularidad: Recogiendo la categoría propia de la regulación general del procedimiento administrativo, el Reglamento consagra el derecho de oposición a los interesados en los términos del art. 21 de la LBPA. Así, se abandona la denominación genérica de perjudicados empleada en los textos anteriores. Con todo, para estos efectos el concepto de interesado se 
construye sobre la existencia del perjuicio en los derechos e intereses legítimos de personas entonces ajenas al procedimiento. Del mismo modo, la norma mantiene la titularidad a mplia del derecho a oponerse, a diferencia de los primeros reglamentos que la reducían al propietario colindante, aunque no se trata de un derecho concedido a cualquier persona, pues exige encontrarse en una posición cualificada respecto del objeto del procedimiento administrativo.

Aunque el inc. 2 del art. 68 emplea la locución "terceros", ella debe entenderse como personas distintas del interesado principal y que, hasta el momento de oponerse, no tenían relación con el procedimiento, no obstante tener o poder asumir la condición de interesados de acuerdo con el art. 21 №s 2 y 3 de la LBPA. Al respecto, esta última disposición considera interesados, además de aquel que lo promueve (numeral 10), a los que, sin haber iniciado el procedimiento, tengan derechos que puedan resultar afectados con la decisión que en el mismo se adopte (numeral 2o), y a aquellos cuyos intereses, individuales o colectivos, puedan resultar afectados por la resolución y se apersonen en el procedimiento en tanto no haya recaído resolución definitiva (numeral 3 ㅇ).

Siendo así, el titular de un derecho potencialmente afectado con la solicitud tiene la condición de interesado per se en el procedimiento, sin necesidad de oponerse ni de realizar alguna actuación en él. Distinta es la posición de aquel que considera que el acto terminal impactará negativamente en un interés legítimo, pues para asumir la calidad de interesado deberá comparecer en el procedimiento, lo que se producirá precisamente al deducir oposición.

e) Requisitos: A diferencia de las regulaciones anteriores, la normativa actual establece en forma explícita que la oposición debe satisfacer los requisitos de toda solicitud, los que se encuentran contenidos en el art. 30 LBPA. Del mismo modo, el inc. 40 del art. 68 ordena que la oposición debe estar acompañada de antecedentes que fundamenten el derecho o interés legítimo del oponente y el perjuicio invocado ( $v$.gr. inscripciones de domino, escrituras públicas, actos administrativos, etcétera), los que de no estar presentes conducirán a su inadmisión.

Respecto de la forma de presentación, la disposición en análisis prescribe que la oposición debe efectuarse a través de la plataforma electrónica que sirve de expediente administrativo, aunque reconoce la posibilidad excepcional de presentarla en formato papel directamente en la Subsecretaría o Capitanía de Puerto respectiva.

f) Oportunidad: el cambio más significativo de la nueva regulación está contenida en el inc. 30 del art. 68, en cuanto incorpora un término para deducir la oposición, estableciendo que "cualquier interesado (...) podrá formular oposición a la solicitud dentro del plazo de 30 días, contado desde la fecha de publicación del extracto".

La adscripción del derecho a oponerse a una oportunidad predeterminada dentro del curso procedimental y la aplicación del principio de preclusión -normalmente ajeno en apariencia a la configuración del procedimiento administrativo-, permiten superar los defectos contenidos en las regulaciones anteriores, que se traducían en un aumento excesivo del plazo de tramitación y en permitir la presentación de oposiciones con la finalidad de obstaculizar el procedimiento.

Si bien puede parecer criticable el acotado lapso para su presentación, el derecho de oponerse de los terceros debe colocarse en la balanza junto con la necesidad de tramitar los procedimientos administrativos en plazos razonables ${ }^{29}$, de manera que el lapso considerado por el Reglamento parece razonable, siendo coincidente con los demás procedimientos especiales que contemplan este mecanismo.

Como se infiere del precepto citado, el plazo de treinta días para deducir oposición se cuenta desde la publicación del extracto en el sitio electrónico de la Subsecretaría. Respecto de las concesiones mayores, dado que además de esa publicación el interesado principal debe publicar el extracto en un diario o periódico, el lapso para oponerse comienza a correr desde que se realiza la última publicación.

${ }^{29}$ SENG (1967), p. 72. 
g) Admisibilidad: En aras de velar porque la oposición tenga una base mínima de seriedad, se establecen como causales de inadmisibilidad la extemporaneidad en su presentación, la manifiesta falta de fundamento y el no estar provista de antecedentes sustentatorios del derecho o interés, así como del perjuicio invocado. Ante alguna de estas hipótesis, el Ministerio la declarará inadmisible, ahorrándose el tiempo que se empleaba en procesar oposiciones que carecían de sustento.

h) Traslado: Admitida a trámite una oposición, el art. 69 ordena a la Subsecretaría notificarla al solicitante, informándole que cuenta con el plazo de 20 días para formular sus alegaciones o, si lo estima conveniente, intentar un acuerdo con el oponente. Esta regla constituye una manifestación directa del principio de contradictoriedad, que permite a los interesados formular sus alegaciones en forma previa a que se adopte la decisión. Al mismo tiempo, reconoce al promotor del procedimiento la posibilidad de alcanzar un acuerdo, sin que el Ministerio inste a que ello tenga lugar ni intervenga en las conversaciones entre los interesados.

De acuerdo con lo prescrito por el precepto aludido, y en concordancia con el art. 26 letra b), el procedimiento se suspenderá durante el término de 20 días desde el traslado.

Por último, cabe precisar que ante el traslado de la oposición el interesado que no esté dispuesto a explorar un acuerdo con el oponente puede formular sus alegaciones o bien abstenerse hacerlo y, en su lugar, presentar un escrito renunciando al mentado plazo, para reducir el efecto suspensivo y avanzar en la tramitación de la oposición.

i) Resultados de la oposición: Frente a la oposición declarada admisible y luego de formulado el traslado, podrá existir un acuerdo entre interesado principal y oponente. En caso contrario, el Ministerio deberá resolver la oposición. Al respecto se presentan los siguientes resultados posibles:

i) Acuerdo: El primer supuesto es que el interesado principal alcance un acuerdo con el oponente, dentro del término de veinte días previsto por el art. 69. En esta hipótesis, el acuerdo deberá constar en escritura pública o instrumento privado autorizado ante notario, el que deberá agregarse al expediente electrónico dentro del aludido espacio de tiempo. Desde el punto de vista del procedimiento, la existencia del acuerdo implicará que su tramitación se reanudará, como indica el inc. 2 이 del art. 70, y no existirá un pronunciamiento sobre la oposición, al ser innecesario por haberse compuesto los intereses en conflicto. Sin perjuicio de lo anterior, el Ministerio deberá pronunciarse sobre el acuerdo en el acto terminal (art. 70 inc. 1ㅇ). Si bien la norma no establece en qué consiste ese pronunciamiento, entendemos que, dado que el otorgamiento de concesiones marítimas es una potestad discrecional, la Administración revisará la suficiencia del acuerdo como un elemento de juicio para adoptar la decisión de acceder o no a la solicitud. Como consecuencia de esa revisión, el Ministerio podrá denegar la solicitud cuando aparezca de la oposición deducida y del acuerdo alcanzado que el proyecto no se ajusta a derecho o al interés público, lo que se producirá cuando impacta negativamente en los derechos e intereses de personas distintas del oponente y que no comparecieron a su suscripción.

ii) Inexistencia de acuerdo: En el evento de no presentarse un acuerdo entre interesado principal y oponente, el Ministerio deberá resolver la oposición. Ante ello, existen naturalmente dos posibilidades: (1) desestimar la oposición, lo que implicará continuar con el procedimiento o (2) acoger la oposición, rechazando la solicitud y poniendo término al procedimiento administrativo (art. 70 inc. 2 ㅇ). Si bien la Administración cuenta con una potestad discrecional para otorgar o no la concesión, en la resolución de la oposición la facultad de decidir su destino dependerá del supuesto que se presente, siendo reglada o discrecional. Entonces, estas hipótesis que determinarán la naturaleza de la decisión que adopte el Ministerio son las siguientes:

- Derechos adquiridos legítimamente sobre el sector, que resultan incompatibles con la concesión (art. 68 inc. 1ㅇ): Si el oponente logra acreditar la existencia de derechos legítimamente 
adquiridos en el sector, cuando la concesión solicitada impida o sea incompatible con su libre ejercicio y no se alcanza acuerdo, la solicitud deberá ser desestimada. En este evento, el Ministerio carece de una potestad discrecional para resolver el conflicto entre los interesados, encontrándose en el imperativo de desestimar la solicitud por tratarse de un supuesto reglado. Acreditado el derecho legítimamente adquirido, la Administración deberá calificar si la concesión que se solicita impide o resulta incompatible con su libre ejercicio, aspecto que entrega al Ministerio cierto margen de apreciación, dependiendo especialmente de la naturaleza del derecho involucrado.

Si se determina que el espacio requerido corresponde a un inmueble de propiedad particular, este solo hecho será determinante para rechazar la solicitud, siendo innecesario avanzar en determinar si la concesión requerida impide o es incompatible con el libre ejercicio del derecho de dominio, puesto que otorgar la concesión implicaría dictar un acto antijurídico ${ }^{30}$.

- Derechos que resultarán perjudicados con la concesión solicitada (art. 68 inc. 2º): La segunda hipótesis corresponde a la presencia de un derecho que se verá perjudicado con el otorgamiento de la concesión, su renovación o su modificación sustancial. Estos derechos pueden recaer en espacios no solicitados en concesión, o bien en el mismo sector requerido, esto último en el evento de que la concesión solicitada no sea incompatible con el libre ejercicio de esos derechos - puesto que si recaen sobre el mismo sector y su ejercicio es incompatible se estará en el supuesto normativo del inc. 10 recién comentado-.

Si el perjuicio que puede irrogar el acceder a la solicitud del interesado principal es lícito, es decir, no implicará una actuación antijurídica, el Ministerio contará con una potestad discrecional para resolver la oposición, debiendo ponderar a la luz de los elementos de juicio que aporta la oposición, si acceder a la solicitud aparece como conveniente para el interés público. A esta conclusión se arriba considerando que la hipótesis reglada se encuentra prevista con nitidez en el inc. 1ㅇ recién comentada, en que se emplea la expresión "no se otorgará la concesión", en contraste con la frase "el Ministerio podrá denegar una solicitud de concesión" empleada por el inciso que le sigue.

- Intereses legítimos perjudicados con la concesión solicitada (art. 68 inc. 2º): Finalmente, será también discrecional la decisión de acoger o no la oposición cuando el interesado accesorio logre demostrar que la concesión solicitada irroga un perjuicio a un interés legítimo. Ello se presentará cuando el usuario de un Área de Manejo de Recursos Bentónicos considere que el otorgamiento de una concesión aledaña puede generar la percepción en la comunidad de que los productos hidrobiológicos provenientes de ese sector están contaminados $\mathrm{y}$, por ende, disminuir su consumo.

j) Vías de impugnación: El último aspecto a comentar corresponde a los medios administrativos para impugnar las decisiones que se adopten como consecuencia de la oposición. Respecto de la inadmisibilidad de la oposición que se decide mediante resolución ministerial exenta, si bien no existe regla expresa sobre el punto, consideramos procedente el recurso de reposición por encontrarse en la hipótesis de impugnabilidad excepcional del acto trámite prevista en el art. 15 inc. 2 LBPA. Lo anterior teniendo en consideración que la inadmisión errónea de la oposición provoca una situación material de indefensión del oponente, el que se verá impedido de ejercer las facultades de actuación en el procedimiento derivadas de su calidad de interesado, sin perjuicio de que es posible estimar, asimismo, que esa actuación intermedia aparece como terminal respecto de ese interesado. Del mismo modo, razones de oportunidad desaconsejan que ese interesado al que se negó su intervención en el procedimiento deba esperar su conclusión para impugnar el acto terminal, generando una innecesaria utilización de recursos. El recurso jerárquico, en tanto, no resultará procedente por tratarse de un acto emitido por un ministro de Estado.

30 Como indica Villar Palasí, el otorgamiento de concesiones conlleva la obligación de mantenimiento del estado posesorio preconstituido, esto es, que no puede afectar derechos civiles adquiridos y que tengan naturaleza real, ni derechos concesionales otorgados previamente por la Administración (siguiendo el aforismo quien es primero en el tiempo, es mejor en derecho). VILLAR (1951), p. 163. 
De acuerdo con el art. 70 inc. final, tanto la desestimación de la oposición como el rechazo de la solicitud de concesión, su renovación o modificación sustancial, que se efectúan también mediante resolución ministerial exenta, son impugnables a través del recurso de reposición, no siendo procedente el jerárquico por la anotada razón. Lo expuesto, como precisa la norma, es sin perjuicio de las demás vías de impugnación que resulten procedentes. Esta elemental regla termina por enterrar definitivamente la existencia de espacios inmunes al control, como el que se consagraba en este ámbito por los reglamentos anteriores al D.S. № 2, de 2005, que contenían la frase "la resolución que recaiga sobre ella no será susceptible de recurso alguno".

\section{Conclusiones}

Las particularidades del procedimiento de otorgamiento de concesiones marítimas y aquellos anexos a este (renovación y modificación), se han traducido en que, históricamente, la regulación reconozca la existencia de terceros que pueden resultar afectados con el acto terminal. Cinco décadas antes de la dictación de nuestra normativa básica de procedimiento administrativo, las reglas sobre la oposición fueron precursoras en admitir que los resultados del procedimiento excedían del interesado promotor, al tiempo que en reconocer derechos de intervención a esos potenciales afectados.

El hecho que el ámbito de las concesiones marítimas aparezca como uno de los espacios en que se encuentra más desarrollada la regulación de la oposición se explica por, a lo menos, dos razones. De una parte, la naturaleza de los bienes concesionables y la forma como se comportan, identifican y registran estos bienes, se traduce en la existencia de una elevada probabilidad de que se otorguen concesiones sobre espacios no susceptibles de ello, ya por no ser administrados por el Ministerio o por haber sido concesionados previamente. Si bien el desarrollo de técnicas de georreferenciación representa un avance en esa delimitación, la existencia de otros órganos con potestades de administración sobre el borde costero afecta también la certidumbre en que lo que se esté concesionando es realmente susceptible de otorgarse en concesión. De otro lado, los múltiples intereses que concurren sobre el dominio marítimo-costero y la creciente presión por su utilización, comportan también que los conflictos en este espacio sean parte del escenario habitual. La insuficiencia de la normativa urbanística y, particularmente, la ausencia de una zonificación del borde costero que defina con precisión los usos que pueden desarrollarse sobre un determinado sector, constituyen factores que incrementan la conflictividad entre concesionarios vecinos con proyectos cuyos efectos exceden el espacio concesionado.

Es en ese contexto que el diseño del mecanismo de oposición se presenta como una pieza clave en el funcionamiento del sistema de administración del demanio marítimo y costero. Al respecto, la regulación de la materia experimentó sucesivos cambios, los que se asentaron con la dictación del D.S. $\mathrm{N}^{\circ} 223$, de 1968. Esa configuración del derecho a oponerse se traspasó al D.S. $\mathrm{N}^{\circ} 2$, de 2005 , cuerpo normativo que, no obstante haberse dictado estando vigente la LBPA, no fue coherente con sus disposiciones. Al mismo tiempo, los defectos de esa regulación en términos de la ausencia de mecanismos de publicidad del procedimiento y de una oportunidad preestablecida para ejercer el derecho de oposición, redundaron en una dilación adicional al extenso tiempo de tramitación de las solicitudes, favoreciendo la aparición de oposiciones con fines obstruccionistas. Estas deficiencias motivaron el nuevo diseño normativo contenido en el D.S. №9, de 2018.

Junto con reorganizar el contenido de la reglamentación de manera más ordenada y coherente, obteniendo un texto que permite un mejor acceso a las materias, el nuevo Reglamento desarrolla con mayor profundidad el mecanismo de oposición. La extensión de la regulación referida a esta materia es indiciaria de su significancia y de que fue necesario rediseñar completamente su configuración, para superar así las insuficiencias de la normativa sustituida. 
Entre los aspectos que se abordaron, los medios de publicidad de la solicitud y del acto terminal, representan elementos relevantes no solo en avanzar hacia la transparencia del procedimiento, sino que, fundamentalmente, de permitir a los - hasta ese momento- terceros el ejercicio de los derechos de intervención que les asisten en su condición de interesados. Luego, la delimitación precisa del mecanismo, excluyendo expresamente la oposición fundada en casos de sobreposición de solicitudes, y la existencia de una instancia de admisibilidad, coadyuvan a despejar oposiciones carentes de sustento, insuficientes o meramente dilatorias.

El término de 30 días para deducir oposición y su fijación en una etapa específica del íter procedimental, unido al reconocimiento expreso del derecho a formular alegaciones por parte del interesado principal y el pronunciamiento del Ministerio sobre el acuerdo que se pueda alcanzar, aparecen también como aspectos centrales de la nueva reglamentación.

Es por lo anterior que la normativa en estudio representa un correcto esfuerzo en equilibrar el derecho de los terceros a intervenir en un procedimiento, con la necesidad de que este se desarrolle en plazos razonables, y en relevar al procedimiento administrativo como sede primaria para la composición de intereses y resolución de conflictos.

\section{BiBLIOGRAFÍA CITADA}

CASSAGNe, JUAN CARLOS (2013): El acto administrativo (Bogotá, Ed. Temis).

Celume Byrne, Tatiana (2013): Régimen público de las aguas (Santiago, Ed. AbeledoPerrot Thomson Reuters).

ChAPELA PÉREZ, MARÍA Rosa (2001): “La ocupación o explotación del dominio público marítimoterrestre para el ejercicio de la acuicultura (a propósito de la STC 9/2001, de 18 de enero, sobre la Ley de Pesca de Galicia)", en: Revista de Administración Pública (№ 156), pp. 337-364.

CONDE Y CONDE, MARIO (1974): "El pretendido uso público de las playas y zona marítimo-terrestre de propiedad particular", en: Revista de Administración Pública (№ 73), pp. 429-454.

FUENTES OlMOS, JeSSICA (2013): "Análisis comparado de los regímenes de las concesiones marítimas y de acuicultura", en: Revista de Derecho de la Pontificia Universidad Católica de Valparaíso (№ XLI, segundo semestre), pp. 411-456.

FuentetAJA PASTOR, Jesús (2003): “Elementos autorizatorios y concesionales en los títulos habilitantes", en: Revista de Administración Pública (№ 160), pp. 87-119.

GonZález PÉREZ, Jesús (2002): Manual de Procedimiento Administrativo (Madrid, Ed. Civitas).

Leguina Villa, Jesús y DesDentado Daroca, EVA (2005): “El régimen jurídico de los terrenos ganados al mar y la preservación del demanio costero", en: Revista de Administración Pública (№ 167), pp. 7-45.

LóPEZ MENUdO, FRANCISCO (2013): "La vieja cláusula «sin perjuicio de tercero» y la Administración del porvenir", en: Revista de Administración Pública (№ 191), pp. 463-480.

LozAno CutANDA, Blanca (2009): Derecho Ambiental Administrativo (Madrid, Ed. Dykinson).

Martín Mateo, Ramón (1985): "Régimen jurídico de los cultivos marinos", en: Revista de Administración Pública (№ 106), pp. 7-56.

Míguez NúÑEZ, Rodrigo (2014): "De las cosas comunes a todos los hombres. Notas para un debate", en: Revista Chilena de Derecho (Vol. 41, № 1), pp. 7-36.

MIRALLES GonZÁleZZ, ISABEL (1992): Dominio público y propiedad privada en la nueva Ley de Costas (Madrid, Ed. Civitas). 
MiroseVic Verdugo, CAMILO (2013): Mecanismos de participación ciudadana en el ordenamiento jurídico (Santiago, Ed. Librotecnia).

RodríGUez MORO, NemeSIO (1967): "Las diversas competencias que concurren en la zona marítimo-terrestre”, en: Revista de Administración Pública (№ 52), pp. 267-306.

Seng, Michael (1967): "Intervention by Third Parties in Federal Administrative Proceedings", en: Notre Dame Law Review (Vol. 42, Issue 1), pp. 71-83.

Villar PALASí, JOsé LUIS (1951): “La Eficacia de la Concesión y la Cláusula sin Perjuicio de Tercero”, en: Revista de Administración Pública ( ${ }^{\circ}$ 5), pp. 147-234.

WAHL, RAINER (2013): Los últimos cincuenta años del Derecho administrativo alemán (Madrid, Ed. Marcial Pons).

\section{NORMAS JURÍDICAS CITADAS}

\section{CóDIGO CIVIL.}

LEY N 18.575, Ley Orgánica Constitucional de Bases Generales de la Administración del Estado. Diario Oficial, 5 de diciembre de 1986.

LEY N 19.880 , Establece Bases de los Procedimientos Administrativos que rigen los Actos de los Órganos de la Administración del Estado. Diario Oficial, 29 de mayo de 2003.

LeY N 18.892, Ley General de Pesca y Acuicultura. Diario Oficial, 21 de enero de 1992.

LEY N 19.542, Moderniza el Sector Portuario Estatal. Diario Oficial, 19 de diciembre de 1997.

LEY N²1.149, Establece Sanciones a quienes impidan el Acceso a Playas de Mar, Ríos y Lagos. Diario Oficial, 14 de febrero de 2019.

D.F.L. N ${ }^{\circ}$ 340, de 1960 del Ministerio de Hacienda, Ley sobre Concesiones Marítimas. Diario Oficial, 6 de abril 1960.

D.L. N 1939, de 1977 del Ministerio de Tierras y Colonización. Diario Oficial, 10 de noviembre de 1977.

D.S. № 12, de 1949, del Ministerio de Defensa Nacional, Reglamento General sobre Concesiones Marítimas.

D.S. N ${ }^{\circ} 156$, de 1961, Ministerio de Defensa Nacional, Reglamento General sobre Concesiones Marítimas. Diario Oficial, 24 de marzo de 1961.

D.S. $N^{\circ} 223$, de 1968, Ministerio de Defensa Nacional, Reglamento sobre Concesiones Marítimas. Diario Oficial, 11 de junio de 1968.

D.S. $N^{\circ} 660$, de 1988 , Ministerio de Defensa Nacional, Reglamento sobre Concesiones Marítimas. Diario Oficial, 28 de noviembre de 1988.

D.S. $N^{\circ} 2$, de 2005, Ministerio de Defensa Nacional, Reglamento sobre Concesiones Marítimas. Diario Oficial, 20 de abril de 2006.

D.S. $N^{\circ}$ 9, de 2018, Ministerio de Defensa Nacional, que sustituye el Reglamento sobre Concesiones Marítimas. Diario Oficial, 17 de marzo de 2018. 